\title{
Medical Specialist Training: Views from Stakeholders
}

\author{
Md Tahir MA a Noor Hazilah AMㄹ, Azura Oc \\ aProfessor, Faculty of Medicine and Deputy Rector (Academic and Planning), International Islamic University \\ Malaysia. \\ ${ }^{b}$ Associate Professor, Kulliyyah of Economics and Management Sciences, International Islamic University \\ Malaysia \\ 'Assistant Professor, Kulliyyah of Economics and Management Sciences, International Islamic University \\ Malaysia
}

\begin{abstract}
Introduction: In Malaysia, medical specialisation training is mainly carried out by the public universities. Methods: A survey was carried out to explore the views of medical specialists in the country on issues such as structure of medical specialty training, availability of human resource, public/private sector competition, competency and apprenticeship, and its impact on assurance and quality of medical specialty training. Results: Altogether 238 medical specialists from 30 hospitals and medical institutions in the country participated in the survey. Conclusion: Among the findings, competition for human resource between public and private sector and lack of uniformity on medical specialty training across universities in the country are among the issues found to be of concern. There is also a need to address governance issue which necessitates to clearly delineating what constitutes medical specialty and what constitutes a subspecialty so that an agreed uniformed nomenclature is exercised across all stakeholders. The respondents also strongly agreed on the need to ensure competence in medical specialist training.
\end{abstract}

KEYWORDS: Medical specialty training, human resource management, healthcare management.

\section{INTRODUCTION}

Medical specialty training generates much interest to both teachers of medicine as well as policymakers. For one thing, a healthy population is an indicator of a country's development status. Apart from that, Malaysia has seen a rapid increase in medical schools over the past few years to the extent that a moratorium was placed on the establishment of new medical schools. ${ }^{1}$ With more than thirty medical schools in the country and more than 370 recognised medical qualifications from abroad, the alarm has been raised on the need to assure quality, not just quantity alone. ${ }^{2}$ The country now produces about 5000 medical graduates a year ${ }^{3}$ and with the increase in the number of graduates, naturally the demand for postgraduate

Corresponding author:

Noor Hazilah Abd Manaf

Department of Business Administration

Faculty of Economics and Management Sciences

International Islamic University Malaysia

P.O Box 10

50728 Kuala Lumpur

Email: hazilah@iium.edu.my

Telephone: 6019-2257416 medical education will also increase. The masters programme has seen an increase of more than 50 percent in intake to nearly 900 places. ${ }^{4}$ As such there is a dire need for continuous research on medical specialty training to be conducted. Nonetheless, this has not been the case and there has been very few studies conducted within the Malaysian context. Rogayah \& Zulkifli ${ }^{5}$ for example explored the timing and stability of choice of medical sepcialty among Malaysian doctors while $\operatorname{Lim}^{1}$ gave a historical and current perspective of medical education in the country, including postgraduate medical education and continuing medical education (CME). Given the dearth in the literature, it is therefore envisaged that this study will fill the lacuna in the body of knowledge.

\section{MATERIALS AND METHODS}

To probe issues on medical specialist training, a focus group session was held with 5 medical specialists - an orthopaedic surgeon, ENT specialist, nephrologist, oncologist and a paediatrician. At the beginning of session, participants were informed of the purpose of study and were also guaranteed full confidentiality of feedback. Informed consent to tape-record the interview was also obtained from all participants. A moderator initiated the discussion with a list of general questions, which served mainly as a guide as participants were encouraged to offer their opinion freely. The interview was transcribed and common issues which emerged as themes affecting medical specialisation were identified. This formed the basis for the research framework. 
Figure 1: Research framework

\section{1) Structure of Specialist Training Model \\ - Specialty / Subspecialty training route and duration \\ - Lack of uniformity across the universities \\ - Varying definition between specialties and subspecialties \\ - Competency and Apprenticeship training}

\section{2) Availability of Human Resource}

- Public and private sector competition

- Innovative ways of remuneration

\section{3) Barriers of entry for specialty / subspecialty training \\ - 'Turfing' of professional bodies}

4) Meeting the Requirement for Postgraduate Training

- Compulsory service

- Subject to release from $\mathrm{MOH}$ for those serving in public sector

- Waiting for place of study

$\rightarrow$ Lengthen the duration to become specialist
Medical Specialist Training

- Assurance

- Satisfaction

- Quality

- Competency

- Future Outlook?

o Research-based specialist training

o Decompartmentalisation between private/ public teaching hospital

\section{6) Governance Issue}

- MOH, MOHE, DG, Conjoint Board, University and Professional Bodies (MMC \& AMM)

\section{Dependent Variable}

\section{Independent variables}

Items based on the above themes were developed for the questionnaire with response ranging from 1 (strongly disagree) to 5 (strongly agree). All the major state hospitals were included as well as some major private hospitals. Due to constraints of time and resources, the survey was limited only to Peninsular Malaysia. Questionnaires were sent to specialists working in universities (7), general hospitals (10), private hospitals (4), the National Heart Institute, Academy of Medicine, and Hospis Malaysia. Altogether 30 hospitals and medical institutions participated in the survey, and a total of 976 questionnaires were sent out to the specialists and subspecialists serving in these organisations. Of these, 238 responses were received which gave a response rate of $24.38 \%$. Data cleaning was carried out to ensure that neither missing values nor outliers were in the data for analysis. Data was analysed by using SPSS 15.

The data was first subjected to an exploratory factor analysis in order for the items to be more manageable and also to identify the constructs latent in the data. Factor analysis carried out by Varimax rotation converged into 10 factors with factor loadings greater than 0.4 for all items. The KaiserMeyer-Olkin (KMO) Measure of Sampling Adequacy was 0.600 indicating adequacy of sample for factor analysis, and Bartlett's Test of Sphericity was significant at an alpha level of 0.000 meaning that factors that form the variables have significant correlations among themselves. The extracted factors were subsequently labelled based on variables identified in the research framework. Cronbach's alpha was found to be 0.491 and although this was less than the recommended 0.7, however, an analysis of individual items revealed very diverse issues covered from human resource to university autonomy; andevennomenclatureinmedicalspeciality. Construction of items for the instrument was also based on data from focus group discussions, rather than published instrument since no prior instrument of the same nature and covering the depth and breadth of the same topic has been developed before. Therefore these factors could have affected the Cronbach's alpha reading. Table I shows the extracted factors, items grouped in each factor, factor loadings, mean and standard deviation of each item. 


\begin{tabular}{|c|c|c|c|c|}
\hline \multicolumn{2}{|c|}{$\begin{array}{ll}\text { Dimension } & \text { Item }\end{array}$} & \multirow{2}{*}{$\begin{array}{l}\text { Factor loading } \\
0.826\end{array}$} & \multirow{2}{*}{$\begin{array}{l}\text { Mean } \\
2.37\end{array}$} & \multirow{2}{*}{$\frac{\text { Std Dev }}{0.994}$} \\
\hline $\begin{array}{l}\text { 1. Private sector } \\
\text { resources }\end{array}$ & $\begin{array}{l}\text { There is adequate regulatory structure within the Ministry } \\
\text { of Health to assure quality in medical specialist training if } \\
\text { private universities are allowed to offer such training. }\end{array}$ & & & \\
\hline & $\begin{array}{l}\text { There is adequate regulatory structure within the Ministry of Higher } \\
\text { Education to assure quality in medical specialist training if private } \\
\text { universities are allowed to offer such training. }\end{array}$ & 0.802 & 2.32 & 0.994 \\
\hline & $\begin{array}{l}\text { The quality of medical specialist graduates will not be affected if } \\
\text { they are trained by private universities/institutions. }\end{array}$ & -0.738 & 2.34 & 1.093 \\
\hline & $\begin{array}{l}\text { Private universities/institutions should be allowed to conduct } \\
\text { medical specialist training. }\end{array}$ & 0.572 & 2.44 & 1.338 \\
\hline
\end{tabular}

2. Meeting the Getting approval from Ministry of Health to enroll in a postgraduate 0.706 requirement for program lengthen the duration to become specialist

Postgraduate

Training

Queuing for release for specialist training from my employer lengthen 0.676

the duration to enroll in the specialist training.

$3.53 \quad 1.199$

Compulsory service with the Ministry of Health does not delay a

0.551

3.46

medical doctor from embarking on his/her specialist training.

3. Public sector resources

There is adequate regulatory structure within the Ministry of Higher

0.767

3.09

1.05

Education to assure quality in medical specialist training in public

institutions in the country.

There is adequate regulatory structure within the Ministry of Health $\quad 0.720$

to assure quality in medical specialist training in public institutions in

the country.

There is inadequate human resource in our local universities to

0.434

2.56

1.119 conduct medical specialist training.

4. Competency The government should explore innovative ways in order to give

0.641

$4.54 \quad 0.633$

and

better remuneration to medical specialists in the public sector

Apprenticeship

training

If we shorten the duration of specialist training, hands-on training

will be compromised and this will affect competency.

In my opinion, apprenticeship is appropriate for all medical specialist 0.524

4.16 trainings.

A structured curriculum is required to ensure competence in medical 0.518 specialist training.

In my opinion, the duration for specialist training I went through is $\quad 0.437$ adequate.

5. Lack of uniformity across the universities
Autonomy given to universities in offering medical specialists training 0.755 contributes to the lack of uniformity in the structure.

In my specialty, there is a lack of uniformity in the programme structure offered by local universities.

0.677

Universities should be given autonomy to develop curriculum for $-0.566$ medical specialist training.

\section{Duration of The duration of training is not an important criterion when choosing 0.725} Training and an area of specialty.

MOH HR planning 
7. Public and private sector competition for human resource
There is a constant flow of medical specialists leaving from the public for the private sector.

The flow of specialists from the public to the private sector produces constraints on medical specialist training at local universities/institutions.
$0.759 \quad 3.99 \quad 0.841$

$0.751 \quad 3.92 \quad 0.960$

8. Governance

Governance issue exists in medical specialists training because

$0.697 \quad 3.89 \quad 1.106$

there are too many governing bodies (Ministry of Health, Ministry of

Higher Education, Conjoint Board, MMC \& Academy of Medicine of

Malaysia).

Nomenclature of medical specialties and subspecialties are not

$-0.6832 .63$

1.017

standardised in this country.

\begin{tabular}{|c|c|c|c|c|}
\hline \multirow[t]{2}{*}{ 9. Barriers of entry } & $\begin{array}{l}\text { The professional bodies keep increasing the entry requirement for } \\
\text { specialist training. }\end{array}$ & 0.749 & 3.21 & 0.928 \\
\hline & $\begin{array}{l}\text { The bar for entry into specialist training varies between specialties/ } \\
\text { subspecialties. }\end{array}$ & 0.540 & 3.76 & 0.747 \\
\hline \multirow[t]{3}{*}{ 10. Skewness } & $\begin{array}{l}\text { Many physicians do not choose their area of specialty based on the } \\
\text { future earnings potential. }\end{array}$ & 0.632 & 2.91 & 1.031 \\
\hline & There are limited places for specialist training in my area of specialty. & 0.607 & 2.89 & 1.189 \\
\hline & $\begin{array}{l}\text { Many physicians choose their area of specialty based on their passion } \\
\text { for the area. }\end{array}$ & -0.585 & 3.93 & 0.778 \\
\hline
\end{tabular}

\section{RESULTS}

\section{Demography}

The respondents comprised $64.3 \%$ male and $33.2 \%$ female. $68.5 \%$ of respondents underwent their medical specialty training locally, while approximately a quarter had their training outside Malaysia. Meanwhile, $2.1 \%$ of the respondents had their medical specialty training in both local and overseas institutions. Majority of the respondents are Malays and other Bumiputera (78.2\%), while 9.2\% and $8.4 \%$ of the respondents are Chinese and Indian respectively. The distribution of respondents covered a comprehensive range of specialties, with participation from 53 areas of specialty. The highest number of respondents comes from internal medicine, with $15.1 \%$ of the total number of respondents. Out of the 238 respondents for the study, 134 respondents (56.3\%) have had their subspecialty training. Of this, 85 subspecialties were reported with a number of specialists having expertise in more than one subspecialty. The most frequently reported subspecialty by the respondents is nephrology $(7.5 \%)$ followed by cardiology and gastroenterology (6.7 and $3.7 \%$ respectively).

\section{Dimensions of Medical Specialty Training}

Strongest agreement among the respondents was for the dimension competency and apprenticeship training (mean 4.42). This was followed by public and private sector competition for human resource (mean 3.95); duration of training and $\mathrm{MOH}$ HR planning (mean 3.49); and barriers of entry (mean 3.49). A low mean score was observed for public sector resources (mean 3.02), and lowest for private sector resources (mean 2.37) as in Table II.

Table II. Mean Analysis of Dimensions of Medical Specialty

\begin{tabular}{lcc}
\hline Factors & Mean & SD \\
\hline Private sector resources & 2.3674 & 0.5162 \\
Meeting the requirement for Postgraduate training & 3.1221 & 0.8589 \\
Public sector resources & 3.0183 & 0.7498 \\
Competency and Apprenticeship training & 4.4160 & 0.4269 \\
Lack of uniformity across the universities & 3.3006 & 0.6852 \\
Duration of Training and MOH HR Planning & 3.4895 & 0.8316 \\
Public and private sector competition for human resource & 3.9536 & 0.7407 \\
Governance & 3.2542 & 0.6531 \\
Barriers of entry & 3.4894 & 0.6625 \\
Skewness & 3.2475 & 0.5522 \\
\hline
\end{tabular}


Regression analysis between dimensions of medical specialty and medical schools/institutions' quality

The respondents were also posed the item 'medical schools/institutions in the country provide good quality specialist training' and this item has a mean of 3.74 and standard deviation 0.884 . Regression analysis was also carried out between dimensions of medical specialty training and item on medical schools/institutions' quality in providing specialist training. Table III(i) shows the R squared value is 0.244 which indicates that 24.4 per cent of variance in medical schools/institutions' quality can be explained by the ten factors of medical speciality training. The F-test as shown in Table III(ii) indicates statistical significance $F(10,204)=6.59$, $\mathrm{p}<0.001$. From Table III(iii), D3 and D4 have $\mathrm{p}$-value of 0.000 and 0.010 (sig. $p<0.05$ ); and factors D5 and D8 have $p$-value 0.062 and 0.098 respectively $(p<0.10)$. This indicates that public sector resources (D3) and competency and apprenticeship training (D4) may predict medical schools/institutions quality at $p<0.05$; while lack of uniformity across universities and governance may predict medical schools/ institutions quality at $p<0.10$. The higher Beta score for D3 indicates that public sector resources is the strongest contributor to the model.

Table III (i). Regression analysis between factors of medical specialty training and medical schools/institutions' quality

Model R R Square Adjusted R Square Std. Error of the Estimate

\begin{tabular}{lllll}
\hline 1 & $.494^{\mathrm{a}}$ & .244 & .207 & .811
\end{tabular}

Table III (ii). ANOVA - medical schools/institutions' quality

\begin{tabular}{lllllll}
\hline & Model & Sum of Squares & $\mathrm{df}$ & Mean Square & $\mathrm{F}$ & Sig. \\
\hline 1 & Regression & 43.373 & 10 & 4.337 & 6.587 & $.000 \mathrm{a}$ \\
Residual & 134.320 & 204 & .658 & & \\
Total & 177.693 & 214 & & & \\
\hline
\end{tabular}

Table III (iii). Coefficients

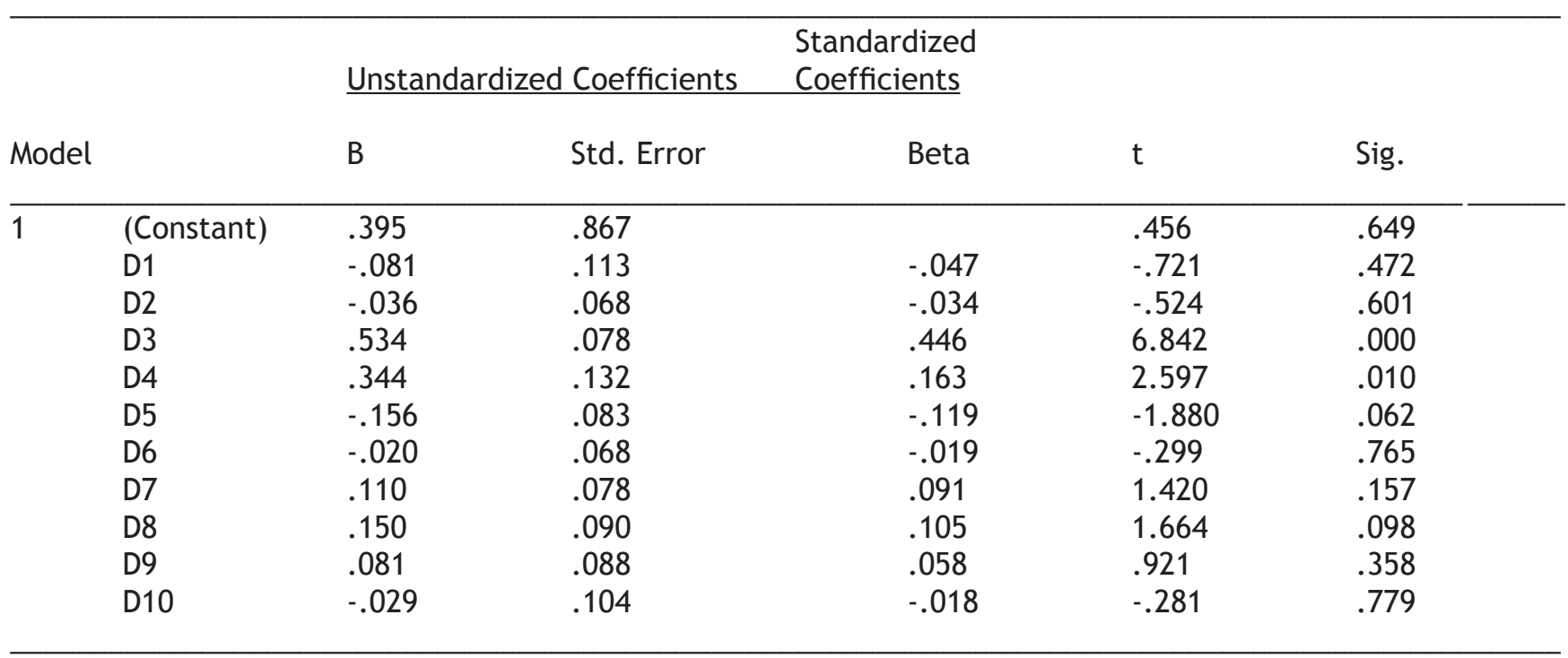




\section{DISCUSSION AND CONCLUSION}

The study explored medical specialists training from the stakeholders' perspectives. Issues and challenges in medical specialty training from the outlooks of medical specialists themselves provided the framework for the study. No doubt medical education in Malaysia has matured over the years and the country has gained much from a sound healthcare delivery system which has raised much of its health indicators to that of a developed nation status. Nonetheless, we cannot be complacent as the dynamism of healthcare can push us to the level of follower once more, rather than leader of the pack, in the region.

The study points to the need to address governance issues with respect to medical subspecialty training. The foundation has to be put right. This necessitates to clearly delineating what constitutes medical specialty and what constitutes a subspecialty so that an agreed uniformed nomenclature is exercised across all stakeholders. At the moment, autonomy given to universities in offering medical specialty training contributes to the lack of uniformity. But this must be done with the patients' interests in mind as it has been deliberated time and again in the literature the economic impact of medical specialisation. And that this led to the manifestation of 'turfing' of professional bodies was also captured in the study. Despite, it is most reassuring that there was a high concurrence among the respondents on the dimension for competency and apprenticeship training in medical specialty. The possibility of exploring apprenticeship rather than the didactic approach alone was also a considered factor in the need to reorientate medical specialty training in the country. However, caution was also expressed for adequate regulatory structure from the Ministry of Health and Ministry of Education, as well as adequate human resource in our local universities, in predicting assurance, satisfaction, quality and competency in medical specialty training.

Other issues affect medical specialty training in the country. With 130 hospitals spread across the length and breadth of the country, the Ministry of Health is still the largest employer of health professionals in the country. Thus, human resource planning by the Ministry of Health, compulsory service, queuing for release for medical specialty training, and getting approval from the Ministry of Health are all compounding issues. Should we tap private sector resources in overcoming the downside of availability of human resource? Granted, agreement was high on the constant flow of medical specialists from the public to private sector (mean 3.99), and that the public-private flow does constraint medical speciality training. But the respondents did not agree for private universities to be allowed to conduct medical specialist training; and the perception is that the regulatory structure within the Ministry of Education and Ministry of Health is inadequate at the mo- ment to address medical specialty training by private universities. Until and unless the infrastructure is in place to assure quality in private universities' training, we have no option but to rely on public sector resources. For this purpose, remunerating medical specialists in public institutions should be addressed to stem the outflow of expertise.

Despite the setbacks, perception on specialty training offered by our medical schools is positive. An interesting point which emerged from the finding is the higher level of confidence expressed by the respondents in the services provided by medical specialists in the public hospitals in comparison to those in the private hospitals. Looking forward, medical specialty in the country needs to free itself from the clutches of public/private dichotomy and teaching/service structure. A seamless stream of knowledge and expertise should be allowed to flow unreservedly regardless if one is in private or public hospital; or teaching or service hospital. Research should not be the domain of the teaching hospitals alone, but those in general hospitals and other institutions too. There is a need to revisit the existing healthcare delivery system for more specialised hospitals to be built as the volume of cases from such hospitals will enhance medical specialty training in the country.

\section{DISCLOSURE ON CONFLICT OF INTEREST}

The authors declared no potential conflict of interest with respect to the authorship and/or publication of this article.

\section{ACKNOWLEDGEMENTS}

The research was funded by the International Islamic University Malaysia through its Endowment research grant. The authors acknowledge IIUM for its support.

\section{REFERENCES}

1. Lim VK. Medical Education in Malaysia. Med Teach 2008; 30:119-23.

2. Lum M. Quality first, not quantity. The Star 2011 Jan 9. Available from: http://www.thestar.com. my/Lifestyle/Health/2011/01/09/Quality-firstnot-quantity/

3. Vijaindren A. No jobs for medical grads next year: Malaysian Medical Association. New Straits Times 2013 Nov 11. Available from: http: //www2.nst. com.my/nation/general/no-jobs-for-medicalgrads-next-year-1.396549

4. Rani MFA. Malaysia needs more teaching hospitals. International Medical Journal Malaysia 2012; 11:2.

5. Rogayah J \& Zulkifli A. The timing and stability of choice of medical specialty among Malaysian doctors. Med J Malaysia 2001; 56:324-30. 